\title{
Effect of Fluegas Flowrate on Sizing of Venturi Scrubber using Aspen Process Tool-Aspen Venturi
}

\author{
Hassan Anwar Saleemi ${ }^{1^{*}}$, Awais Ashraf ${ }^{2}$ \\ ${ }^{1}$ Lecturer, Chemical Engineering Department, Sharif College of Engineering \& Technology, Off Raiwind \\ Road, Lahore-54000, PAKISTAN \\ ${ }^{2}$ Undergraduate Student, Chemical Engineering Department, Sharif College of Engineering \& Technology, \\ Off Raiwind Road, Lahore-54000, PAKISTAN \\ Corresponding Contact: \\ Email: hassananwer17@yahoo.com
}

\begin{abstract}
Design of the preheat venturi scrubber has been performed using the process tool ASPEN Venturi by ASPEN Process Tool V 8.0- aspen one. Venturi scrubbers can be design using either the flowrate of gas at inlet conditions or the saturated gas flowrate. Various input parameter introduced in this research to be specified for sizing which included, Liquid to Gas ratio is kept $3.339 \mathrm{Litre} / \mathrm{m}^{3}$, Gas pressure drop is $4.9835 \mathrm{kPa}$, Entering gas temperature at standard conditions is $371.1^{\circ} \mathrm{C}$ and Liquid (water) volumetric flowrate is $0.000794 \mathrm{~m}^{3} / \mathrm{sec}$. It is observed that higher values of Liquid to Gas ratio gives a higher pressure drop. As most commonly, Liquid and gas enters at converging section, or liquid can also be introduced from throat. As area decreases, gas velocity increases and pressure drop becomes higher which in accordance to Bernoulli's Equation. By keeping all the parameter constant likewise Liquid to Gas ratio and Gas pressure drop for all the process. At gas flowrate $0.2 \mathrm{~m}^{3} / \mathrm{sec}$ and $1.4 \mathrm{~m}^{3} / \mathrm{sec}$, we get Throat Velocity $43.94 \mathrm{~m} / \mathrm{sec}$ and $106.3 \mathrm{~m} / \mathrm{sec}$, Throat Diameter $0.07613 \mathrm{~m}$ and $0.13 \mathrm{~m}$ and Throat Length $1.6 \mathrm{~m}$ and $0.205 \mathrm{~m}$, respectively. From graphical trend, it is proved that Gas flowrate is directly proportional to Throat velocity and diameter and inversely proportional to Throat length.
\end{abstract}

Key words

Venturi Scrubber, Modeling, ASPEN Process Tool, Venturi Design

$6 / 1 / 2016$

Source of Support: None, No Conflict of Interest: Declared

This article is is licensed under a Creative Commons Attribution-NonCommercial 4.0 International License.

Attribution-NonCommercial (CC BY-NC) license lets others remix, tweak, and build upon work non-commercially,

and although the new works must also acknowledge \& be non-commercial.

\section{INTRODUCTION}

Venturi scrubbers are gas cleaning devices, especially used for applications acquiring very high collection efficiencies of particles generally between 0.5 to $5.0 \mu \mathrm{m}$ in diameter 
(www.nepis.epa.gov). The term scrubbing refers to a process of removing particulate from a gas stream by contact with liquid. Schematic representation of Venturi scrubber is shown in figure 1. They employ gradually converging and then diverging sections to clean an incoming gaseous stream. It consist of a convergent section, a throat and a divergent sections. In general, the longer the throat, the higher the collection efficiency at a given pressure drop, provided the throat is not so long that frictional losses become significant. To effect higher removal efficiency, pressure drop between the venturi inlet and throat is increased to promote greater turbulence and agglomeration (Geoffrey, 2004).

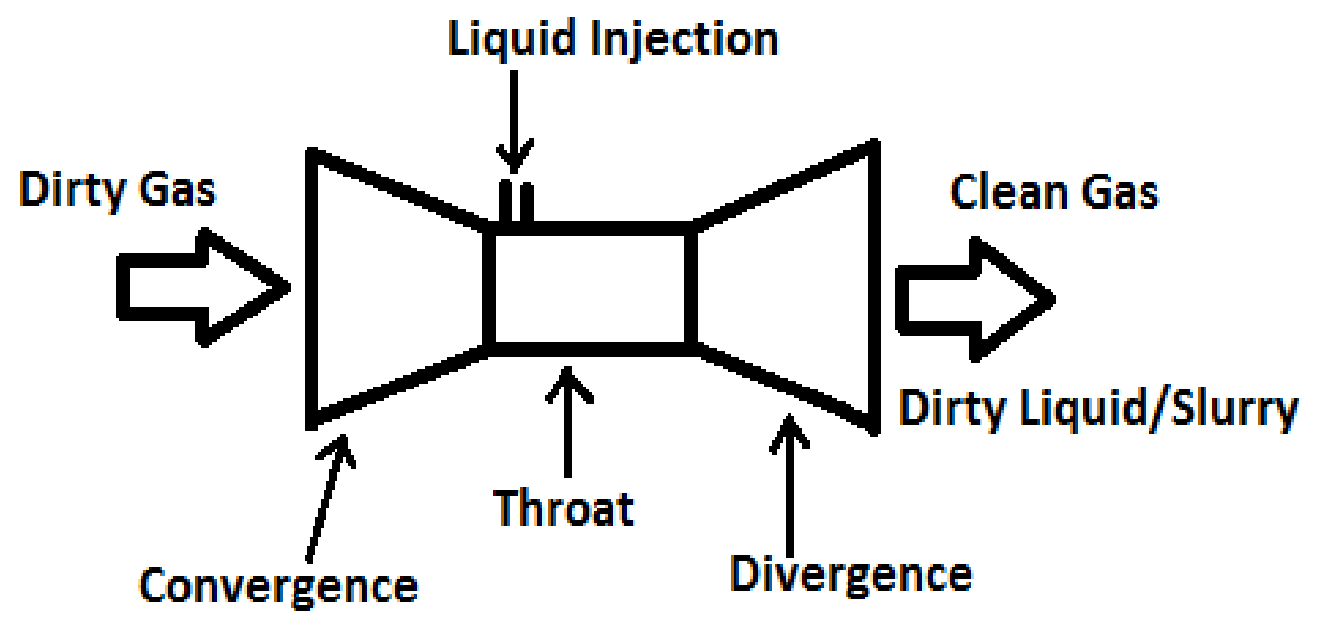

Figure 1: Schematic Diagram of venturi scrubber

Once the liquid is atomized, it begins to collect particles from the gas impacting into the liquid as a result of the difference in velocities of the gas stream and the atomized droplets. As the mixture decelerates in the expanding section, further impaction occurs causing the droplets to agglomerate (Douglas, 1981). Once the particles have been trapped by the liquid, a separator (e.g. cyclone, demisters, swirl vanes) can readily remove the scrubbing liquid from the cleaned gas stream (www.en.citizendium.org).

The sizing of venturi scrubber is measured by consideration of its collection efficiency and pressure drop. Performance is studied with respect to design parameters like throat length, throat diameter and throat velocity (Desai and Omprakash, 2014). Gas velocity in throat is dominant to breakup liquid into droplets. L/G ratio is kept very low, while pressure drop and collection efficiency are studied under the light of operating conditions like L/G ratio, gas velocity at entry and at throat (Ali et al., 2012).

We have done this study on Aspen Process Tool-Aspen Venturi. ASPEN stand for Advance System for Process Engineering. Aspen Venturi software is used for the design and sizing of Venturi scrubbers for particle collection duties. The program provides two functions: to calculate the pressure drop required to achieve a given particle collection efficiency and to calculate the geometry of Venturi required to achieve that pressure drop. Venturi also allows existing scrubbers to be performance rated. 


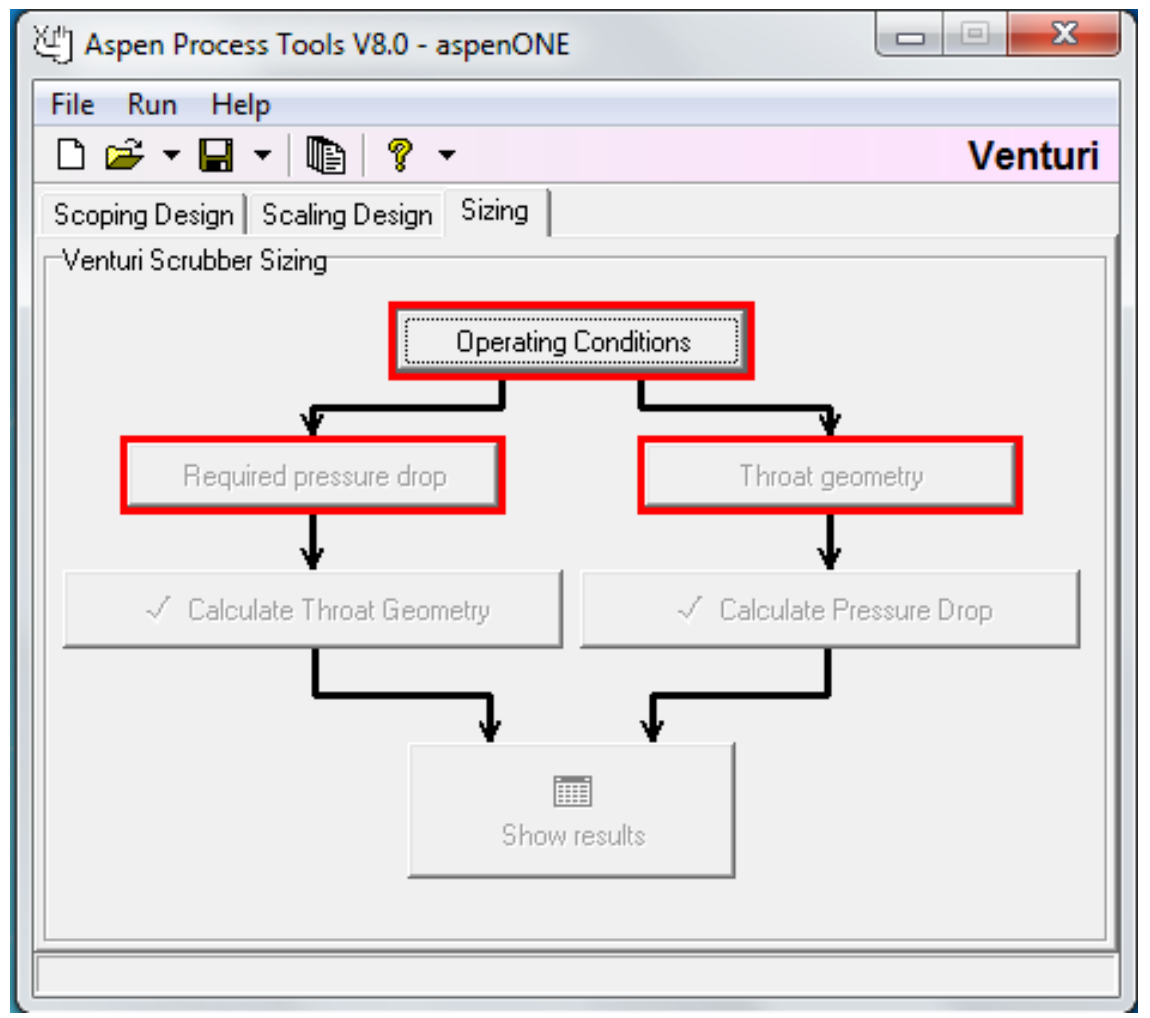

Figure 2: Main page of Aspen Process Tool-Aspen Venturi

\section{Materials AND Methods}

During the design of a venturi scrubber, various parameters needed to be specified which included, Liquid to gas ratio (typical values exist between 10-30 gal/1000 $\mathrm{ft}^{3}$ of gas), Gas pressure drop (less than 80 inches $\mathrm{H}_{2} \mathrm{O}$ ), Liquid volumetric flow rate, Gas volumetric flow rate and Gas entering temperature.

The main parameters that were needed to be calculated preliminary, included the throat diameter and the throat length. The following values of parameters have been selected and fed to software:-

- The liquid to gas ratio is proposed to be $20 \mathrm{gal} / 1000 \mathrm{ft}^{3}$ or $3.339 \mathrm{~L} / \mathrm{m}^{3}$.

- The gas pressure drop, in case of fluidized bed preheaters/dryers, has a range between 20-30 inches of $\mathrm{H}_{2} \mathrm{O}$. A value of 20 inches of $\mathrm{H}_{2} \mathrm{O}$ is proposed for the design. This value is equal to 0.72279 psi or $4.9835 \mathrm{kPa}$.

- The gas (flue gas) flow rate at standard conditions is $405 \mathrm{ft}^{3} / \mathrm{sec}$ or $11.468 \mathrm{~m}^{3} / \mathrm{sec}$.

- The entering gas temperature is approximately $700^{\circ} \mathrm{F}$ or $371.1^{\circ} \mathrm{C}$.

- The liquid (water) volumetric flow rate is $0.2098 \mathrm{gal} / \mathrm{sec}$ or $0.000794 \mathrm{~m}^{3} / \mathrm{sec}$ (with reference to material balance process water requirement section).

The process tool, by default, is capable of handling SI unit system. So, the input values to the process tool are in SI units, which are also specified above. By plugging in the values of the required parameters, the process tool generated values of throat diameter, throat diameter and velocity of gas at the throat inlet. 


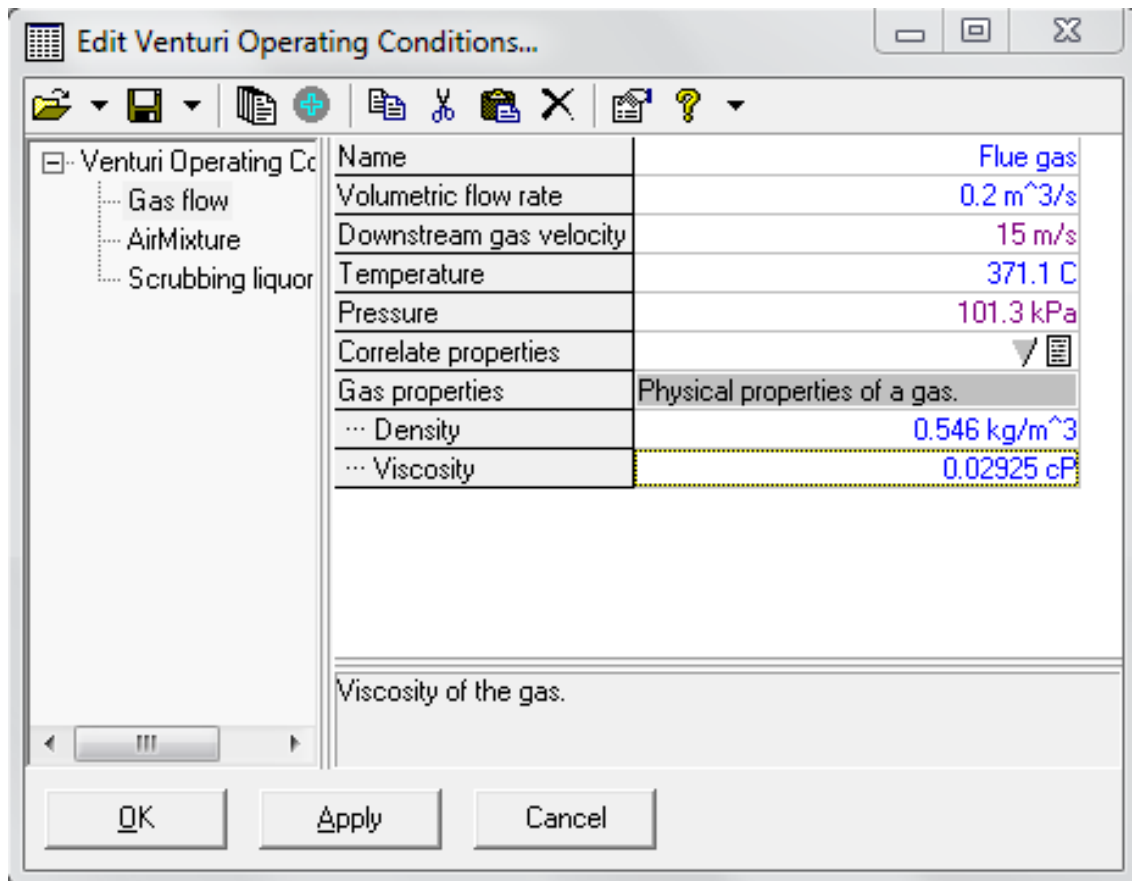

Figure 3: Input Plugin to Aspen Venturi

雁 Edit Venturi Operating Conditions...

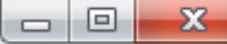

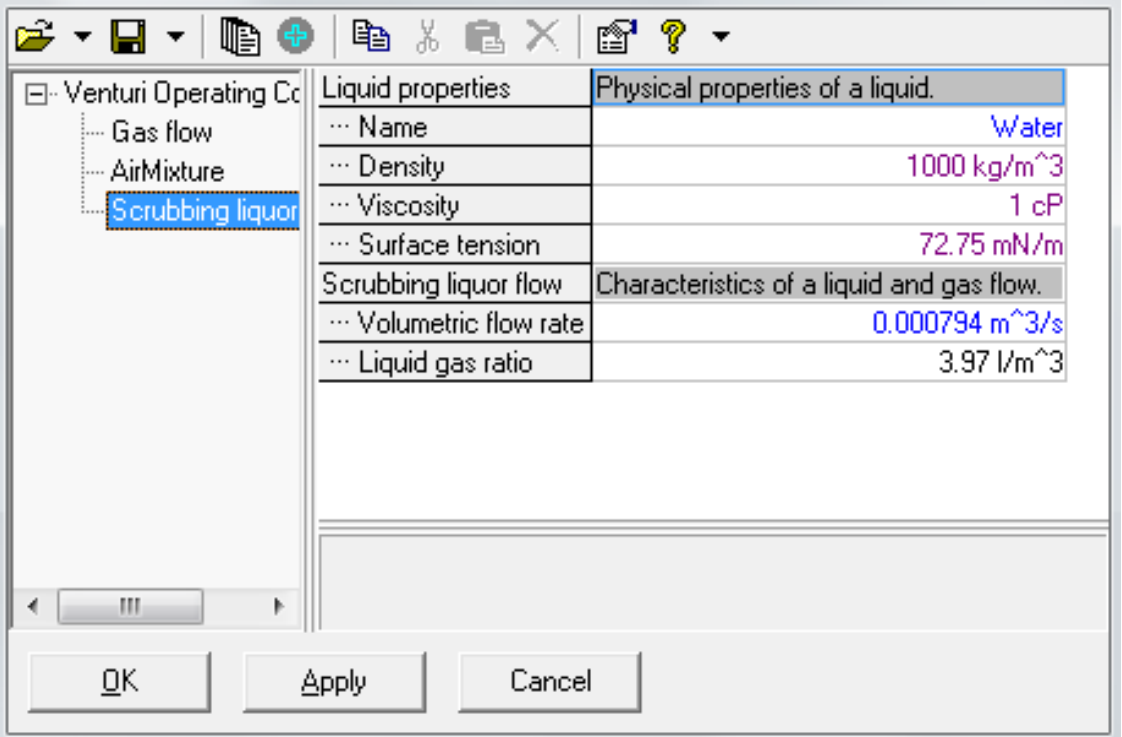

Figure 4: Input Values to Aspen Venturi 


\begin{tabular}{|c|c|c|}
\hline \multicolumn{3}{|c|}{ 嘈 Edit Required Pressure Drop... } \\
\hline 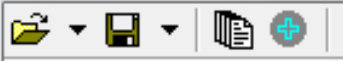 & 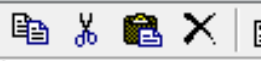 & \\
\hline Venturi design & \multicolumn{2}{|c|}{ Parameters characterising the design of a venturi scrubber. } \\
\hline$\cdots$ Pressure drop & & $4.984 \mathrm{kPa}$ \\
\hline$\cdots$ Diffuser angle & & 6Degres \\
\hline Droplet flow & \multicolumn{2}{|c|}{ Characteristics of the flow of liquid droplets in a gas stream. } \\
\hline$\cdots$ Droplet/gas velocity ratio & & 0.8 \\
\hline \multicolumn{3}{|c|}{$\begin{array}{l}\text { The angle at which the Venturi diffuses with respect to the centre line. Typical values are } 3-8 \\
\text { degrees, with } 15 \text { degrees seen as a practical maximum }\end{array}$} \\
\hline Bppl & Cancel & \\
\hline
\end{tabular}

Figure 5: Values of Pressure and Angle

After applying the values, the process tool converged,

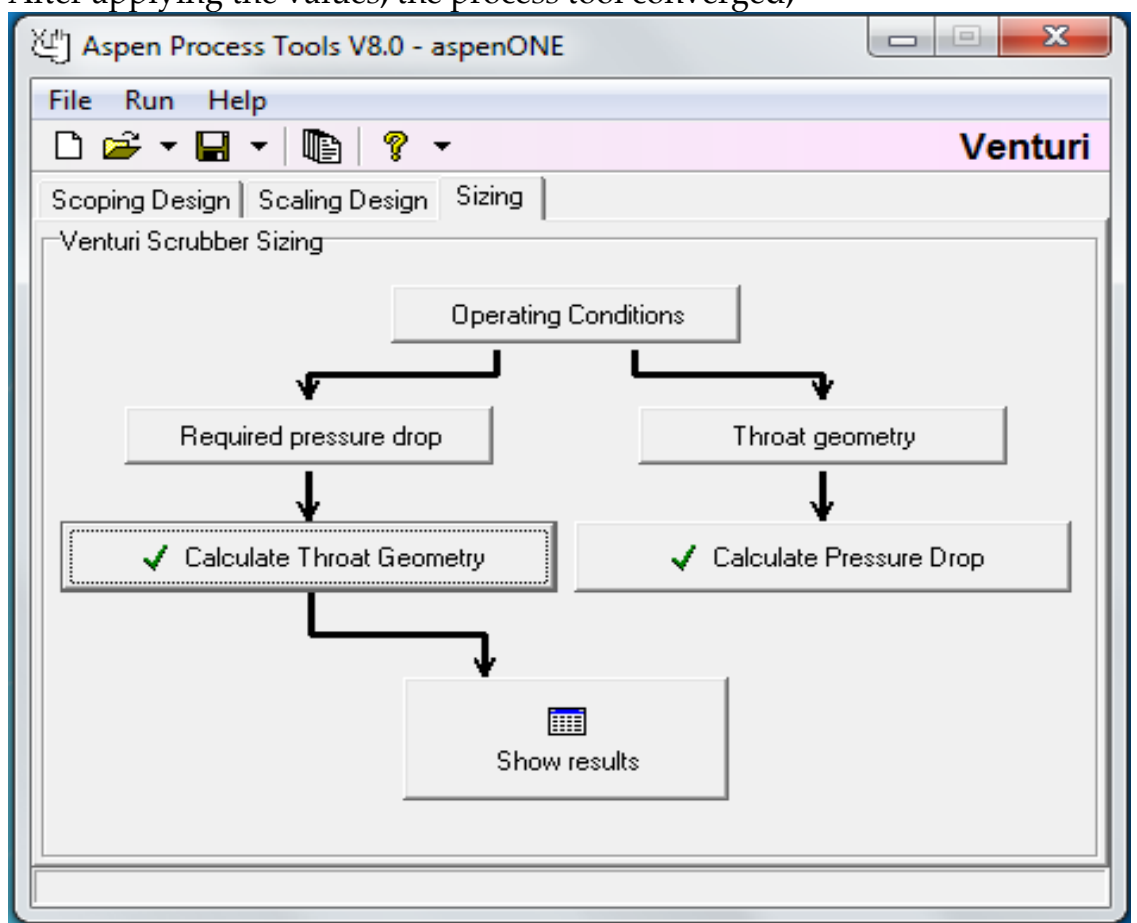

Figure 6: Convergence of Aspen Venturi

After all these steps performed above we are able to get three design parameters like: Throat length, Throat Diameter and Throat velocity. Venturi tubes are used in processes where permanent pressure loss is not tolerable and where maximum accuracy is needed in case of highly viscous liquids. Convergence deals with the variation of Pressure drop 
across the venturi tube length through different diameters which show variation in velocity of the gas.

\section{RESULTS AND Discussion}

The measured and calculated values obtained from venturi sizing calculated results are presented in following table.

Results Produced by Aspen Venturi Process Tool

\begin{tabular}{|c|c|c|}
\hline Size Case Result & & \\
\hline Venturi sizing calculation & esults & \\
\hline Droplet flow & & \\
\hline Pressure drop & 4.985 & $\mathrm{kPa}$ \\
\hline Dry pressure drop & 0.06452 & $\mathrm{kPa}$ \\
\hline Wet pressure drop & 4.9231 & $\mathrm{kPa}$ \\
\hline Mean droplet size & 279.4 & um \\
\hline Droplet/gas velocity ratio & 0.8 & \\
\hline Venturi design & & \\
\hline Throat velocity & 47.72 & $\mathrm{~m} / \mathrm{s}$ \\
\hline Throat diameter & 79.66 & $\mathrm{~mm}$ \\
\hline Throat length & 1340 & $\mathrm{~mm}$ \\
\hline
\end{tabular}

Thus the required parameters to meet the scrubbing requirement include, Throat diameter $=80 \mathrm{~mm}$ equivalent to 31 inches and throat length $1340 \mathrm{~mm}$ (53 inches).

\section{Effect of Gas Flow rate $\left(\mathrm{m}^{3} / \mathrm{sec}\right)$ of sample on Throat Velocity $(\mathrm{m} / \mathrm{sec})$}

From graph and table given below, we can observe that as a gas flow rate of sample increases throat velocity also increases.

Gas flowrate $\propto$ Throat velocity

\begin{tabular}{|c|c|}
\hline Gas Flowrate $\left(\mathbf{m}^{3} / \mathbf{s e c}\right)$ & Throat Velocity $\mathbf{( m / s e c )}$ \\
\hline 0.2 & 43.94 \\
\hline 0.4 & 60.76 \\
\hline 0.6 & 73.1 \\
\hline 0.8 & 83.19 \\
\hline 1.0 & 91.83 \\
\hline 1.2 & 99.45 \\
\hline 1.4 & 106.3 \\
\hline
\end{tabular}

The volumetric gas flow rate, $\mathrm{Q}$ (measured in SI units $\mathrm{m}^{3} / \mathrm{sec}$ ), of a fluid flowing through the venturi at any given instant is the product of the cross-sectional area, measured in $\mathrm{m}^{2}$ at that point multiplied by the fluid's linear velocity, $v(\mathrm{~m} / \mathrm{s})$, at that point. Since the volumetric flow rate is the constant value within the venturi, the linear velocity of the fluid traveling through the smaller diameter throat of the venturi must increase which results in a decrease of pressure due to the conservation of energy law. 


\section{Throat Velocity $(\mathrm{m} / \mathrm{sec})$}

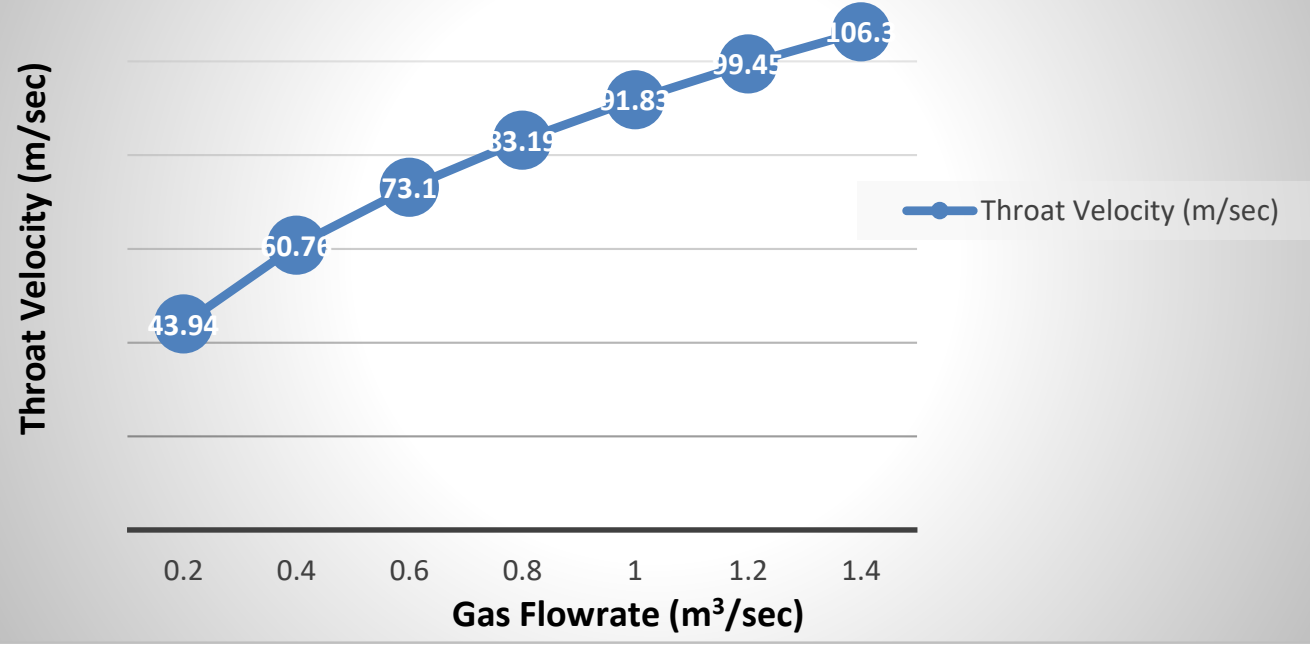

Owing to variation in radius from venturi flowrate meter at the entrance to venturi tube throat average velocity is exchanging from 40 to $120 \mathrm{~m} / \mathrm{sec}$, while temperature and pressure conditions remain constant. As at $0.2 \mathrm{~m}^{3} / \mathrm{sec}$, throat velocity is round about 45 $\mathrm{m} / \mathrm{sec}$, as it proceed further, there is a gain in kinetic energy resulting from increased linear velocity in the throat is quite offset by the decrease of pressure in the throat section. At the maximum after passing through convergent, throat and divergent region it gains a value of $110 \mathrm{~m} / \mathrm{sec}$, which is due to smaller area and pressure value. It is observed clearly that the linear velocity in the throat is higher than the linear velocity in the inlet section.

\section{Effect of Gas Flow rate $\left(\mathrm{m}^{3} / \mathrm{sec}\right)$ of sample on Throat Diameter $(\mathrm{mm})$}

For the same values of gas flowrate tested against throat diameter, dependent variable goes on increasing with the increase of independent variable directly proportional to each other. Values are formulated thorough with the aid of aspen venturi tool and are represented in tabular form are given below:-

\begin{tabular}{|c|c|}
\hline Gas Flowrate $\left.\mathbf{~ m}^{\mathbf{3}} \mathbf{s e c}\right)$ & Throat Diameter $\mathbf{( m m )}$ \\
\hline 0.2 & 76.13 \\
\hline 0.4 & 91.55 \\
\hline 0.6 & 102.2 \\
\hline 0.8 & 110.7 \\
\hline 1.0 & 117.7 \\
\hline 1.2 & 124 \\
\hline 1.4 & 129.9 \\
\hline
\end{tabular}

For the value of $0.2 \mathrm{~m}^{3} / \mathrm{sec}$ of gas volumetric flowrate, throat diameter is $76 \mathrm{~mm}$, while it gain the maximum value of $130 \mathrm{~mm}$ as gas flowrate advances to $1.4 \mathrm{~m}^{3} / \mathrm{sec}$. Variation in the diameters are due to construction design of venturi meter. 


\section{Throat Diameter (mm)}

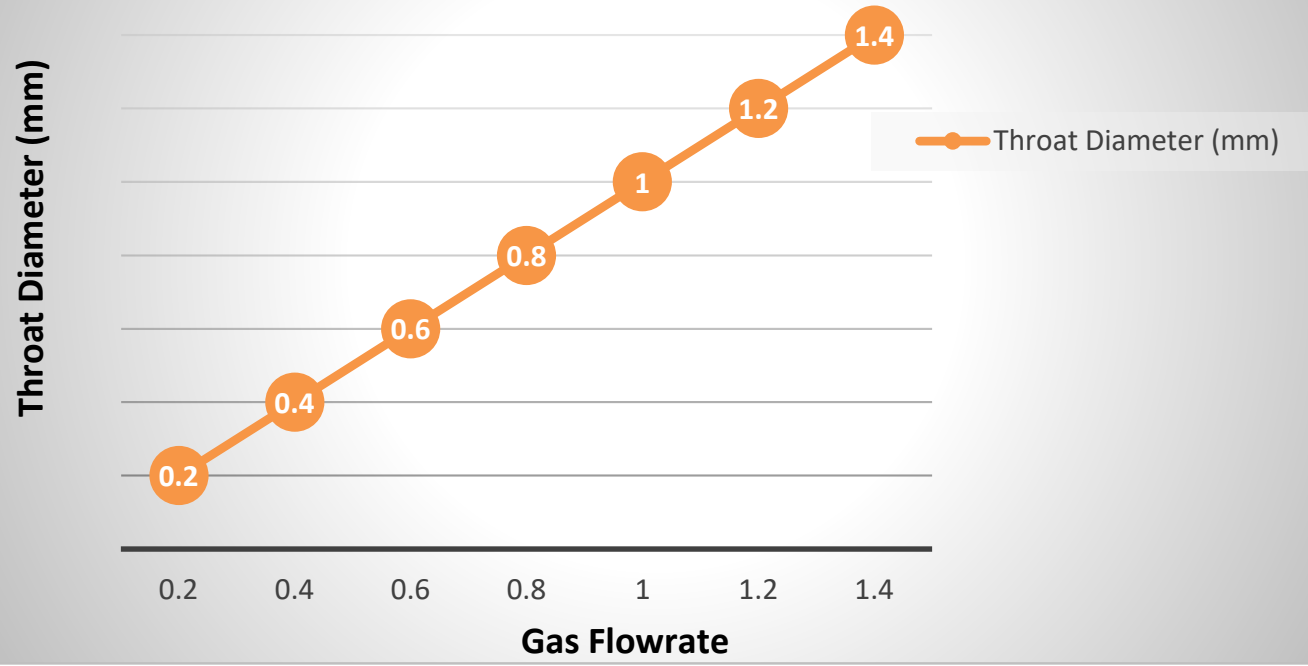

Internal inlet venturi tube diameter is small in size as compared to diameter of venturi tube throat where maximum gas flow velocity and minimum pressure is created. Throat diameter becomes larger due to increase in gas volumetric flowrate as by graphical trend, which indicates that maximum static pressure is transformed to dynamic pressure and lot of pressure drop is created. Change in diameters are basically responsible for converting kinetic energy to pressure energy.

\section{Effect of Gas Flow rate $\left(\mathrm{m}^{3} / \mathrm{sec}\right)$ of sample on Throat Length $(\mathrm{mm})$}

Again the values of gas flow rate were remain kept constant with same increment at $0.2,0.4,0.6$ up to $1.4 \mathrm{~m}^{3} / \mathrm{sec}$ an inverse effect of throat length has been observed throughout the experiment values. First at the initial values the trend was sharp decrease in the length due to decrease in area and increase in the velocity by keeping the overall pressure constant, as obeyed according to equation of continuity.

\begin{tabular}{|c|c|}
\hline Gas Flowrate $\left.\mathbf{( m}^{\mathbf{3}} \mathbf{s e c}\right)$ & Throat Length $\mathbf{( m m )}$ \\
\hline 0.2 & 1658 \\
\hline 0.4 & 678.9 \\
\hline 0.6 & 434.6 \\
\hline 0.8 & 328.2 \\
\hline 1.0 & 269.2 \\
\hline 1.2 & 231.8 \\
\hline 1.4 & 205.9 \\
\hline
\end{tabular}

As the value from 0.4 to $1.4 \mathrm{~m}^{3} / \mathrm{sec}$, the throat length kept on decreasing with steady state trend unless until we get the value of $206 \mathrm{~mm}$ for the gas flowrate of $1.4 \mathrm{~m}^{3} / \mathrm{sec}$. 


\section{Throat Length $(\mathrm{mm})$}

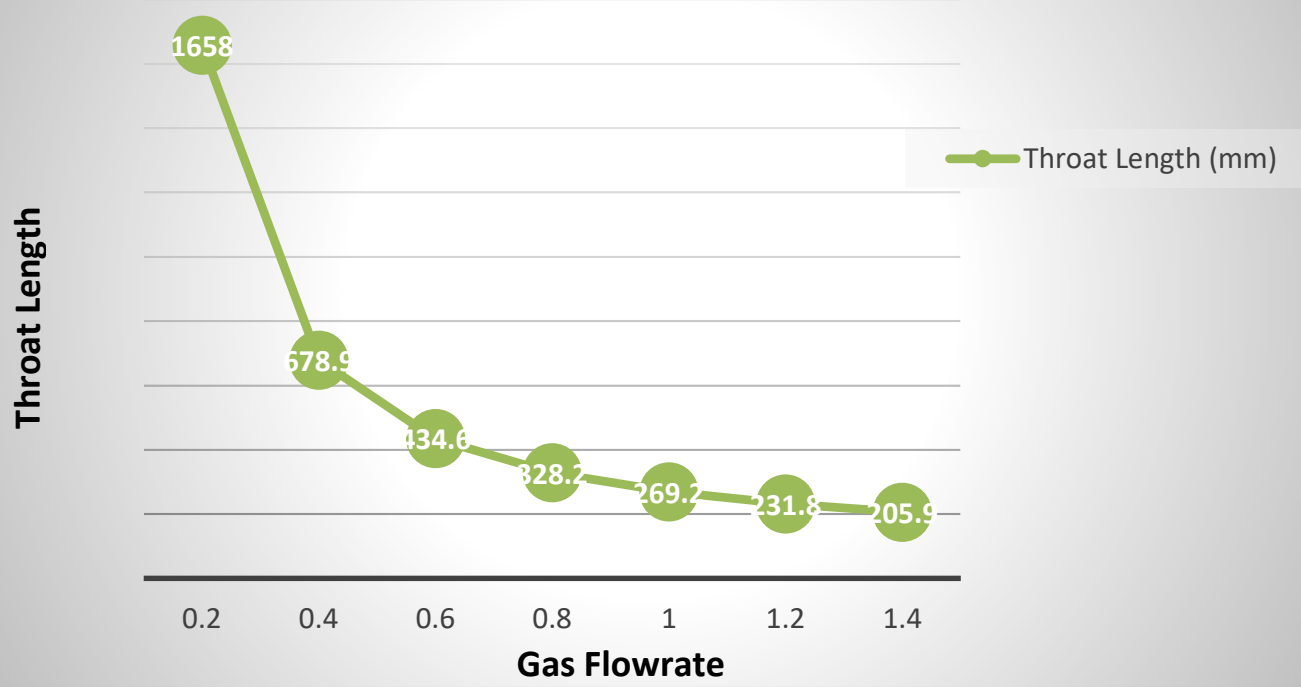

\section{Conclusions}

Using a Simulated software named under the heading of Aspen Venturi tool, we have highlighted the effect of gas volumetric flow rate occurring in a wet approach venturi scrubber type and calculated its throat velocity, throat diameter and throat length used as a symbol of sizing operation. The main results are summarized as follows:-

- The gas first exceeds sharply in convergent region and attain the maximum velocity in throat section and then it start decelerating in diffuser section. Velocity reaches the highest value of $110 \mathrm{~m} / \mathrm{sec}$ on passing through the throat because of the effect of section area of this region.

- The evolution of throat diameter is quite similar to that of velocities and is conform to the venturi effects. The throat diameter reaches a maximum value of $1.4 \mathrm{~mm}$ at the crossing of the gaseous mixture through venturi throat.

- Sharp decrease in achieving the throat length by increasing the values of gas volumetric flow rate is due to change in cross sectional area of the convergent and divergent section of venturi.

This work is helpful to upgrade the sizing of venturi design for better and optimize results.

\section{ACKNOWLEDGEMENTS}

The authors are indebted to Prof. Dr Anwar Rashid Saleemi, Member Technical Punjab Environment Tribunal, for the financial and logistics support in this research.

\section{REFERENCES}

Ali, Majid, Chang Qi Yan, Zhong Ning Sun, Jian Jun Wang, and Athar Rasool." CFD Simulation of Throat Pressure in Venturi Scrubber", Applied Mechanics and Materials, 2012.

Ali, Majid, Chang Qi Yan, Zhong Ning Sun, Jian Jun Wang," Study of Pressure Drop Model for SelfPriming Venturi Scrubber", 2012 Asia- Pacific Power and Energy Engineering Conference, 2012. 
Desai, R., and Omprakash Sahu. "Study of Venturi Scrubber Efficiency for Pesticide Industry", International Letters of Natural Sciences, 2014.

Douglas Roberts. "Atomization in a venturi scrubber", Chemical Engineering Communications, 1981.

Geoffrey D. Silcox. "Hazardous Waste Incinerators", Kirk-Othmer Encyclopedia of Chemical Technology, 2004.

Mirshams, M., H.Taei, M.Ghobadi, and H.Haghi. "Spacecraft attitude dynamic simulator actuated by cold gas propulsion system", Proceedings of the Institution of Mechanical Engineers Part G Journal of Aerospace Engineering, 2015.

www.en.citizendium.org (Internet Source).

www.lorien.ncl.ac.uk, corribgaspipelineabpapplication.ie.

www.me.engin.umich.edu (Internet Source).

www.nepis.epa.gov (Internet Source).

www.sustainedperformance.com, Submitted to PSB Academy (ACP eSolution).

ISSN: 2409-3629

Online Archive Link: $\underline{\text { https://abc.us.org/ojs/index.php/ei/issue/archive }}$ 